\title{
Exploring the Ethnic Identity of Youth from Ethnic Minority and Majority Groups in Viet Nam
}

\author{
Le To Do Quyen ${ }^{1} \&$ Norzarina Mohd-Zaharim ${ }^{1}$ \\ ${ }^{1}$ School of Social Sciences, Universiti Sains Malaysia, Penang, Malaysia \\ Correspondence: Le To Do Quyen, School of Social Sciences, Universiti Sains Malaysia, 11800USM Pulau \\ Pinang, Penang, Malaysia. Tel: 612-460-2399. E-mail: gamen20032003@gmail.com
}

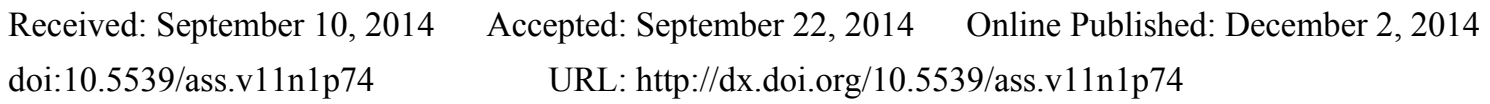

\begin{abstract}
This paper aims to examine and compare the ethnic identity of youth from the ethnic minority and majority groups in Viet Nam. Students' ethnic identity was assessed by applying Multigroup Ethnic Identity Measure (MEIM) (Phinney, 1992). The participants were conveniently selected from a total of 800 students in two colleges and two high schools. The results indicated that for youth from ethnic minority groups, the level of ethnic identity search component (a developmental and cognitive component) was higher compared to affirmation, belonging, and commitment component (an affective component). No significant difference was found between male and female students in these two components otherwise there was significant difference on the ethnic identity search component between college and high school students. In contrast, the score of ethnic identity search component of the majority group was lower compared to the score of affirmation, belonging, and commitment component. Significant differences were found between genders for the affirmation, belonging, and commitment component as well as between high school and college students for the ethnic identity search component. Overall, the scores of youth from ethnic minority and majority groups were high and similar, and there was only one significant difference found in the ethnic identity search component between these two groups.
\end{abstract}

Keywords: ethnic identity, youth, Viet Nam, ethnic minority

\section{Introduction}

\subsection{Ethnic Identity}

Ethnic identity can be defined as the sense of belonging to an ethnic group and it is also the results of ethnic group membership in the part of thinking, perceptions, feeling, and behavior (Rotheram \& Phinney, 1987, p.13). According to Smith and Silva (2001), ethnic identity is the degree of being included and aligned with an ethnic group that individuals perceive themselves (p. 42). Phinney (2000), on other hand, considered ethnic identity as individuals' central defining characteristic, particularly for individuals who are memberships of minority groups (p. 256). The spiritual significance of ethnic identity among minor ethnic groups can be endorsed to discrimination and variation practiced by each group (Tajfel \& Turner, 1986).

In developmental psychology, most research on ethnic identity has mostly been based on Erikson's theories of ego identity improvement (Erikson, 1968). Phinney is well known for his studies that focused on the processes of exploration and commitment (Phinney, 1989, 1990, 1992, 2000, 2006). Ethnic identity search (exploration) is the degree to which youth discover the sense of their attachment to ethnic groups, such as learning about their family heritage and cultural practices or participating in shared events with participants of the same ethnic group and in cultural traditions. Ethnic belonging (commitment) is the extent to which youth feel a positive connection with their ethnic group, such as feeling happy or having a strong sense of pride to be a member of their ethnic group. Thus, high levels of ethnic identity search and belonging indicate a strong ethnic identity (Phinney, 1992). Phinney said that one of the major developmental tasks of adolescence and emerging adulthood is the construction of an ethnic identity. Ethnic identity contributes an essential component to healthy overall identity and a well-established self-concept for youth (Phinney, 1992, 2006). Ethnic identity has always been considered as an important aspect of identity development and therefore leading to many positive psychological outcomes in adolescence for ethnic minority youth (Phinney, 1989, 2006; Yip, Seaton, \& Sellers, 2006). Previous studies have shown that higher levels of ethnic identity are associated with higher self-esteem in youth (AJ, 2004). 
Further, less depression and better overall psychological adjustment were also found in adolescence with a high level of ethnic identity (AJ, 2004; Yip et al., 2006).

\subsection{The Question for Ethnic Identity of Youth from Ethnic Majority and Minority Groups in Viet Nam}

The census of 1st April, 2009 noted the population of Vietnam is around approximately at 85.8 million. As a homeland of many peoples, Viet Nam has 54 ethnic groups, including a major ethnic group and 53 minor ethnic groups. The biggest ethnic groups are Kinh (Viet) 86.2\%, Tay 1.9\%, Tai Ethnic 1.7\%, Mường 1.5\%, Khmer Krom (Khơ Me Crộm) 1.4\%, Hoa 1.1\%, Nùng 1.1\%, Hmong 1\%, others 4.1\% (1999 census). In other words, among ethnic minorities, the most populous are Tay, Thai, Muong, Hoa, Khmer, Nung, etc. with around one million residents for each. Meanwhile, the smallest populous are Brau, Roman, Odu with just almost hundreds citizens for each (Wikipedia, 2014). The majority Kinh flourished in creating a central dominion in the 10th century. The Cham groups also achieved a blossoming culture very early in the olden times. Similarly, the Tay, Nung, and Khmer groups touched the high levels of community improvement with the existence of numerous public strata. The Muong, H'mong, Dao, Thai groups usually gather based on the instruction of their own local ancestral leaders. Some minority communities separated their inhabitants into social echelons, specially individuals living in mountainous regions like Ede or Gia Rai (Nguyen, 2008).

Different ethnic groups mastered different farming techniques. Principles and religions of the Vietnamese minority ethnic groups are also different among themselves (Aradmin, 2012; Nguyen, 2008). Common state of residence of ethnic groups in Viet Nam is coexistence. This trend of residence tends to increase and creates favorable conditions for each ethnic group to strengthen relations in all fields; to enhance mutual understanding and progress in the life and to develop production; to expand the economic and cultural exchanges among groups; to implement the policy, the comparison of the Party and the laws of the State. The level of socioeconomic development is unequal among ethnic groups, and this is due to many different causes, especially with the extreme difficulty of natural conditions in the residential areas of some ethnic minority groups. An obvious gap in the substantial and ethical life undeniably still exists among people living in the deltas and societies in mountainous zones as well as among minority groups themselves (Aradmin, 2012).

Throughout the history of the nation, all the ethnic groups live together in patriotism, unity and mutual assistance in the natural conquest as well as in social struggles. Living close to others, they know the cultures of others by daily interactions. On the other side, in cultural exchange contexts caused by the diversity of the cultures among ethnic groups, they try to keep the identity of their own cultures. Consequently, they are still involved in the common development of the whole nation, whereas each of them is just as a particularity in tune with the generality in the twofold set of philosophy (Nam, 2004). Learning and exchanging values and cultures are happening as a widespread phenomenon that lead to complicated issues for the ethnic minority groups. Accordingly, youth from minority communities in Viet Nam have more chance to communicate with those from the major groups, for example: study, live or work together. Most of them prefer the less different to the major group and the less suffered from racial discrimination. Thus, they try to find strategies in order to hide their special ethnic characteristics and join the major group. Once belonging to the dominant group, they hope that they can easily get large boosts in status, reach important goals, and refine and clarify their own self-concepts by that membership (Baron, Byrne, \& Branscombe, 2006). They even willing to pay a high price - decreasing or losing their ethnic identity - to attain a position in dominant or major groups and get the certainly important benefits.

The Vietnamese Government has operated detailed plans and singular managements to help mountainous societies catch up with publics live in the delta, and paid a lot of concentrates on developing and preserving traditional cultural characteristics of each minority ethnic group. Up to now, various programs for reviewing and increasing traditional culture of each minority ethnic group have obtained acceptable outcomes (Aradmin, 2012). But these are few recent research conducted on exploring psychological factors of youth from ethnic groups.

\section{Research Method}

\subsection{Participants}

Although Viet Nam is the homeland for 53 ethnic minority groups and one ethnic majority group, only randomly selected youth from some specific ethnic minority groups who were attending high school and college in Dak Lak - a large province located in the Central Highlands of Viet Nam - were recruited. Dak Lak Province is well known by the largest number of ethnic minority groups in Viet Nam. There are about 44 ethnic minority groups in Dak Lak Province. They are about 30\% of the whole province's residents. The Ede, M'nong and J'rai are the main native or aboriginal groups, while many others have emigrated since more than the past 30 years, e.g. Tay, Nung, Muong, Dao, Thai and Mong. Almost all of these groups are still preserving their racial tradition which 
contributing an unusual variety of ethnic life in the Central Highlands of Viet Nam called Tay Nguyen. While the ethnic minority groups do not strictly inhabit unglued regions within province, tribes almost live together in the same areas (Daklak provincial people's committee portal, 2010).

The participants were selected by non-probability and convenience sampling method. The sample was youth from ethnic minority groups and ethnic majority group, those were studying in high schools and colleges in Dak Lak province, Viet Nam. It is impossible to deal with all the ethnic groups in a highly complicated multi-ethnic society such as Viet Nam, so some groups were chosen in Dak Lak. 800 students (400 students from ethnic minority groups and 400 students from the ethnic majority group) were recruited. The sample was recruited from two public high schools, two boarding ethnic schools, one ethnic youth vocational college and two public colleges by purposive sampling. 100 students from each public high school, 100 students from each boarding ethnic school, 100 students from each public college and 200 students from ethnic youth vocational college were recruited. The age of participants ranged from 14 to 27, but the Mean of participants' age was 17.52 (SD = 2.789).

\begin{tabular}{cccccc}
\hline \multirow{2}{*}{ Race } & \multicolumn{2}{c}{ Gender } & \multicolumn{2}{c}{ Education } & \multirow{2}{*}{ Total } \\
\cline { 2 - 5 } & Male & Female & High school & College & \\
\hline Major & 150 & 250 & 200 & 200 & 400 \\
Minor & 113 & 287 & 200 & 200 & 400 \\
Total & 263 & 537 & 400 & 400 & 800 \\
\hline
\end{tabular}

Figure 1. Demographics of the study population

\subsection{Measurement}

The main object of this study is exploring the ethnic identity of youth from ethnic groups in Viet Nam by gender and education. Ethnic identity was assessed by using Multigroup Ethnic Identity Measure (MEIM) (Phinney, 1992). The revised (12-item) MEIM (Phinney, 1992) is a worldwide measure of ethnic identity which included two sub scales. It was designed to assess two components of ethnic identity: ethnic identity search (a developmental and cognitive component) and affirmation, belonging, and commitment (an affective component). The two factors are measured separately: factor "ethnic identity search" is measured by items $1,2,4,8$, and 10 and factor "affirmation, belonging, and commitment" is measured by items 3, 5, 6, 7, 9, 11, 12 .

All of items are rated on a four-point scale ranging from $1=$ strongly disagree to $4=$ strongly agree $(4=$ Strongly agree, 3 = Agree, 2 = Disagree, $1=$ Strongly disagree), thus high scores indicate strong ethnic identity. The scoring used the mean of items' scores; in this case, the mean score of total 12 items for overall, and, if preferred, the mean score of the 5 items for ethnic identity search component and the mean score of 7 items for affirmation, belonging, and commitment component. Thus, the scores are ranging from 1 to 4 and the averaging responses for items of each sub scale yielded continuous scores. Furthermore, by constructing dichotomous categories for each scale (high 5 score above the median; low 5 score below the median), participants were classified using the four quadrant system delineated by Phinney (1989): achieved (high on both scales), moratorium (low on affirmation, belonging, and commitment - high on ethnic identity search), foreclosed (high on affirmation, belonging, and commitment - low on ethnic identity search), and diffused (low on both scales).

In the first paragraph of the MIEM, researchers can revise the suggested names of ethnic groups to adapt with specific populations. Items 13,14 , and 15 were used only for racial identification and categorization. The MEIM also includes a six-item scale to assess orientation towards other ethnic groups. The other-group orientation scale is considered to be a detached construct and can be used in conjunction with the MEIM. For the purpose of this study, this part of MEIM was not included.

In this study, forward translation method was used for questionnaire translating from the English version to Vietnamese version. The translated questionnaire was sent to Vietnamese psychologists as well as to English experts for editing and correcting.

The reliability of MEIM (Vietnamese version) for high school students and college students were $\alpha=0.69$ and $\alpha$ $=0.76$, respectively. Overall, the Cronbach's alpha of MEIM was 0.73. Phinney (1992) informed an internal consistency of $\alpha=0.81$ for high school students and 0.90 for college students. As in the study of Rayle and Myers (2004), Cronbach's alpha coefficients for the total sample for the MEIM subscales, respectively, were 
0.61 and 0.67 as well as the corresponding alpha coefficients for ethnic minority and majority participants were 0.54 and 0.59 , and 0.61 and 0.67 . So, they came to conclude that the subscale reliability, overall, was not all that high in their study and it made them question these adolescents' knowledge of ethnic identity. In this study, the reliability of MEIM for high school students, college students and overall were acceptable.

Independent samples t-test was conducted to explore education, gender and ethnic differences in ethnic identity.

\subsection{Procedure}

The written permission from headmasters of schools and colleges were obtained. After that, we explained the objectives of this study to the respondents to get informed consent from those who were willing and interested to take part in this study. For the high schools, researcher and research assistants visited each class to deliver the questionnaires to students at a suitable time. For the colleges, we arranged an appointment with students and they came in a big group of 200 students and answered the questionnaires in a big lecture hall. The questionnaires were administered to the respondents. The researcher and research assistants helped the respondents in answering the questionnaire and answer any question that the respondents might have.

\section{Results}

\subsection{Ethnic Identity of Youth from the Ethnic Majority Group}

Comparing ethnic identity search component of youth from the ethnic majority group of education and gender was shown in Table 1.

Table 1. Ethnic identity search component of ethnic identity for the ethnic majority group

\begin{tabular}{|c|c|c|c|c|c|}
\hline Items & & & $M$ & $S D$ & $t(p)$ \\
\hline \multirow[t]{4}{*}{ Spend time to learn } & \multirow[t]{2}{*}{ Education } & High school & 2.99 & .642 & \multirow{2}{*}{$1.485(.138)$} \\
\hline & & College & 2.88 & .738 & \\
\hline & \multirow[t]{2}{*}{ Gender } & Male & 2.93 & .800 & \multirow{2}{*}{$-.264(.792)$} \\
\hline & & Female & 2.95 & .606 & \\
\hline \multirow[t]{4}{*}{ Active in ethnic organizations } & \multirow[t]{2}{*}{ Education } & High school & 2.60 & .687 & \multirow{2}{*}{$-2.796(.005 *)$} \\
\hline & & College & 2.79 & .687 & \\
\hline & \multirow[t]{2}{*}{ Gender } & Male & 2.74 & .690 & \multirow{2}{*}{$1.400(.162)$} \\
\hline & & Female & 2.64 & .693 & \\
\hline \multirow[t]{4}{*}{ Think about group membership } & \multirow[t]{2}{*}{ Education } & High school & 1.87 & .815 & \multirow{2}{*}{$-2.056\left(.040^{*}\right)$} \\
\hline & & College & 2.05 & .878 & \\
\hline & \multirow[t]{2}{*}{ Gender } & Male & 2.02 & .893 & \multirow{2}{*}{$1.377(.169)$} \\
\hline & & Female & 1.90 & .813 & \\
\hline \multirow[t]{4}{*}{ Talked to others about the group } & \multirow[t]{2}{*}{ Education } & High school & 2.80 & .778 & \multirow{2}{*}{$-1.695(.091)$} \\
\hline & & College & 2.93 & .723 & \\
\hline & \multirow[t]{2}{*}{ Gender } & Male & 2.73 & .827 & \multirow{2}{*}{$-2.539(.011 *)$} \\
\hline & & Female & 2.92 & .704 & \\
\hline \multirow[t]{4}{*}{ Participate in cultural practices } & \multirow[t]{2}{*}{ Education } & High school & 2.86 & .809 & \multirow{2}{*}{$-2.870(.004 * *)$} \\
\hline & & College & 3.10 & .785 & \\
\hline & \multirow[t]{2}{*}{ Gender } & Male & 2.85 & .930 & \multirow{2}{*}{$-2.058(.040 *)$} \\
\hline & & Female & 3.02 & .717 & \\
\hline
\end{tabular}

Note. ${ }^{*} \mathrm{p}<.05 ; * * \mathrm{p}<.005 ; * * * \mathrm{p}=.001 ; * * * * \mathrm{p}<.001$.

The data indicates that there are significant differences found on three items "Active in ethnic organizations" $(t(350)=-2.796, p<.05)$, "Think about group membership" $(t(333)=-2.056, p<.05)$, "Participate in cultural practices" $(t(357)=-2.870, p<.005)$ between high school and college students while there are two significant differences between boys and girls found on items "Talked to others about the group" $(t(275)=-2.539, p<.05)$ and "Participate in cultural practices" $(t(254)=-2.058, p<.05)$. 
As can be seen in Table 2, when comparing affirmation, belonging, and commitment component between high school and college students, significant differences were found on two items "Clear sense of ethnic background" $(t(347)=-2.610, p<.05)$, "Sense of belonging to a group" $(t(304)=-2.103, p<.05)$. Whilst, four items had significant differences between boys and girls: "Sense of belonging to a group" $(t(272)=-2.925, p<.005)$, "Understand group membership" $(t(280)=-3.206, p=.001)$, "Pride in ethnic group" $(t(259)=-4.004, p<.001)$ and "Feel good about the culture" $(t(265)=-3.444, p=.001)$.

Table 2. Affirmation, belonging, and commitment component of ethnic identity for the ethnic majority group

\begin{tabular}{|c|c|c|c|c|c|}
\hline Items & & & $M$ & $S D$ & $t(p)$ \\
\hline \multirow[t]{4}{*}{ Clear sense of ethnic background } & \multirow[t]{2}{*}{ Education } & High school & 3.00 & .747 & \multirow{2}{*}{$-2.610(.009 *)$} \\
\hline & & College & 3.20 & .758 & \\
\hline & \multirow[t]{2}{*}{ Gender } & Male & 2.99 & .790 & \multirow{2}{*}{$-1.727(.085)$} \\
\hline & & Female & 3.13 & .733 & \\
\hline \multirow[t]{4}{*}{ Happy to be a member } & \multirow[t]{2}{*}{ Education } & High school & 3.38 & .809 & \multirow{2}{*}{$.579(.563)$} \\
\hline & & College & 3.33 & .985 & \\
\hline & \multirow[t]{2}{*}{ Gender } & Male & 3.30 & .873 & \multirow{2}{*}{$-1.051(.294)$} \\
\hline & & Female & 3.40 & .891 & \\
\hline \multirow[t]{4}{*}{ Sense of belonging to a group } & \multirow[t]{2}{*}{ Education } & High school & 3.06 & .639 & \multirow{2}{*}{$-2.103\left(.036^{*}\right)$} \\
\hline & & College & 3.21 & .781 & \\
\hline & \multirow[t]{2}{*}{ Gender } & Male & 2.99 & .773 & \multirow{2}{*}{$-2.925(.004 * *)$} \\
\hline & & Female & 3.20 & .648 & \\
\hline \multirow[t]{4}{*}{ Understand group membership } & \multirow[t]{2}{*}{ Education } & High school & 2.86 & .618 & \multirow{2}{*}{$-1.901(.058)$} \\
\hline & & College & 2.99 & .739 & \\
\hline & \multirow[t]{2}{*}{ Gender } & Male & 2.78 & .722 & \multirow{2}{*}{$-3.206(.001 * * *)$} \\
\hline & & Female & 3.00 & .627 & \\
\hline \multirow[t]{4}{*}{ Pride in ethnic group } & \multirow[t]{2}{*}{ Education } & High school & 3.45 & .816 & \multirow{2}{*}{$.768(.443)$} \\
\hline & & College & 3.38 & .981 & \\
\hline & \multirow[t]{2}{*}{ Gender } & Male & 3.20 & .997 & \multirow{2}{*}{$-4.004(.000 * * * *)$} \\
\hline & & Female & 3.56 & .785 & \\
\hline \multirow[t]{4}{*}{ Strong attachment to group } & \multirow[t]{2}{*}{ Education } & High school & 3.04 & .657 & \multirow{2}{*}{$-1.070(.285)$} \\
\hline & & College & 3.12 & .827 & \\
\hline & \multirow[t]{2}{*}{ Gender } & Male & 3.02 & .773 & \multirow{2}{*}{$-1.165(.245)$} \\
\hline & & Female & 3.11 & .706 & \\
\hline \multirow[t]{4}{*}{ Feel good about the culture } & \multirow[t]{2}{*}{ Education } & High school & 3.32 & .758 & $457(648)$ \\
\hline & & College & 3.28 & .862 & $.45 /(.040)$ \\
\hline & Gender & Male & 3.13 & .892 & $-3444(001 * * *)$ \\
\hline & & Female & 3.41 & .724 & ) (.01) \\
\hline
\end{tabular}

Note. ${ }^{*} \mathrm{p}<.05 ; * * \mathrm{p}<.005 ; * * * \mathrm{p}=.001 ; * * * * \mathrm{p}<.001$.

That the component ethnic identity search of youth from the ethnic majority group was strong with the mean of this component being almost equal for college and high school students $(M=2.75(S D=.375)$ and $M=2.62(S D$ $=.395))$ as well as for boys and girls $(M=2.65(S D=.438)$ and $M=2.68(S D=.360))$. Furthermore, affirmation, belonging, and commitment component of youth from the ethnic majority group was even stronger than the ethnic identity search component. The mean of this component for college students $(M=3.21(S D$ $=.569))$ was higher than that of high school students $(M=3.15(S D=.411))$ while the mean for boys $(M=3.05$ $(S D=.514))$ was lower than girls' $(M=3.25(S D=.447))$. 
In other words, the ethnic identity of youth (both male and female students from high school and college) from the ethnic majority was foreclosed (high on affirmation, belonging, and commitment - low on ethnic identity search), but the significant differences were found between genders for the affirmation, belonging, and commitment component $(t(280)=-4.061, p<.001)$ and between high school and college students for the ethnic identity search component $(t(361)=-3.208, p=.001)$. For the whole two components, there were significant differences between genders $(t(267)=-3.330, p=.001)$ and education levels $(t(309)=-2.223, p<.05)$.

\subsection{Ethnic Identity of Youth from Ethnic Minority Groups}

For ethnic identity search component of youth from ethnic minority groups, the data from t-test by education and gender in Table 3 demonstrated two significant differences between high school and college students items: "Active in ethnic organizations" $(t(310)=-3.811, p<.001)$, "Think about group membership" $(t(305)=-2.753$, $p<.005)$ ).

Table 3. Ethnic identity search component of ethnic identity for ethnic minority groups

\begin{tabular}{|c|c|c|c|c|c|}
\hline Items & & & $M$ & $S D$ & $t(p)$ \\
\hline \multirow[t]{4}{*}{ Spend time to learn } & \multirow[t]{2}{*}{ Education } & High school & 2.99 & .687 & \multirow{2}{*}{$-.470(.638)$} \\
\hline & & College & 3.03 & .704 & \\
\hline & \multirow[t]{2}{*}{ Gender } & Male & 2.98 & .756 & \multirow{2}{*}{$-.588(.557)$} \\
\hline & & Female & 3.03 & .674 & \\
\hline \multirow[t]{4}{*}{ Active in ethnic organizations } & \multirow[t]{2}{*}{ Education } & High school & 2.57 & .688 & \multirow{2}{*}{$-3.811(.000 * * * *)$} \\
\hline & & College & 2.85 & .735 & \\
\hline & \multirow[t]{2}{*}{ Gender } & Male & 2.88 & .729 & \multirow{2}{*}{$2.331\left(.020^{*}\right)$} \\
\hline & & Female & 2.70 & .726 & \\
\hline \multirow[t]{4}{*}{ Think about group membership } & \multirow[t]{2}{*}{ Education } & High school & 1.89 & .943 & \multirow{2}{*}{$-2.753\left(.006^{*}\right)$} \\
\hline & & College & 2.17 & .988 & \\
\hline & \multirow[t]{2}{*}{ Gender } & Male & 2.15 & .956 & \multirow{2}{*}{$1.062(.289)$} \\
\hline & & Female & 2.03 & .989 & \\
\hline \multirow[t]{4}{*}{ Talked to others about the group } & \multirow[t]{2}{*}{ Education } & High school & 3.01 & .687 & \multirow{2}{*}{$-.365(.715)$} \\
\hline & & College & 3.04 & .762 & \\
\hline & \multirow[t]{2}{*}{ Gender } & Male & 2.98 & .767 & \multirow{2}{*}{$-728(.467)$} \\
\hline & & Female & 3.04 & .723 & \\
\hline \multirow[t]{4}{*}{ Participate in cultural practices } & \multirow[t]{2}{*}{ Education } & High school & 3.02 & .726 & \multirow{2}{*}{$-.559(.577)$} \\
\hline & & College & 3.07 & .800 & \\
\hline & \multirow[t]{2}{*}{ Gender } & Male & 3.18 & .710 & \multirow{2}{*}{$2.068(.039 *)$} \\
\hline & & Female & 3.00 & .793 & \\
\hline
\end{tabular}

Note. ${ }^{*} \mathrm{p}<.05 ; * * \mathrm{p}<.005 ; * * * \mathrm{p}=.001 ; * * * * \mathrm{p}<.001$

In addition, two significant differences between boys and girls (items: "Active in ethnic organizations" $(t(204)=$ $2.331, p<.05)$ and "Participate in cultural practices" $(t(227)=2.068, p<.05)$.

There were only two significant differences: "Pride in ethnic group" $(t(349)=2.962, p<.005)$, "Feel good about the culture" $(t(313)=2.468, p<.05)$ while comparing affirmation, belonging, and commitment component between high school and college students from ethnic minority groups (see Table 4). No significant difference between genders was found for this component.

For overall, the data suggested that: the mean of the ethnic identity search component (a developmental and cognitive component) for youth from ethnic minority groups was lower than the mean of the affirmation, belonging, and commitment component (an affective component). So, the ethnic identity of youth (both male and female students from high school and college) from ethnic minority groups was also foreclosed like the ethnic identity of youth from the majority group. The mean of the ethnic identity search component of college students $(M=2.82(S D=.419)$ was higher than that of high school students $(M=2.69(S D=.347))$, but it was 
reversed for the mean of the affirmation, belonging, and commitment component $(M=3.16(S D=.562)$ for college students and $M=3.24$ ( $S D=.435$ ) for high school students). Between boys and girls, the means of both two components were higher for boys than for girls.

Table 4. Affirmation, belonging, and commitment component of ethnic identity for ethnic minority group

\begin{tabular}{|c|c|c|c|c|c|}
\hline Items & & & $M$ & $S D$ & $t(p)$ \\
\hline \multirow[t]{4}{*}{ Clear sense of ethnic background } & \multirow[t]{2}{*}{ Education } & High school & 3.06 & .767 & \multirow{2}{*}{$-.498(.619)$} \\
\hline & & College & 3.10 & .811 & \\
\hline & \multirow[t]{2}{*}{ Gender } & Male & 3.10 & .767 & \multirow{2}{*}{$.234(.815)$} \\
\hline & & Female & 3.08 & .807 & \\
\hline \multirow[t]{4}{*}{ Happy to be a member } & \multirow[t]{2}{*}{ Education } & High school & 3.50 & .730 & \multirow{2}{*}{$1.491(.137)$} \\
\hline & & College & 3.37 & .889 & \\
\hline & \multirow[t]{2}{*}{ Gender } & Male & 3.49 & .769 & \multirow{2}{*}{$1.001(.318)$} \\
\hline & & Female & 3.39 & .862 & \\
\hline \multirow[t]{4}{*}{ Sense of belonging to a group } & \multirow[t]{2}{*}{ Education } & High school & 3.08 & .683 & \multirow{2}{*}{$.245(.807)$} \\
\hline & & College & 3.06 & .750 & \\
\hline & \multirow[t]{2}{*}{ Gender } & Male & 3.16 & .727 & \multirow{2}{*}{$1.633(.103)$} \\
\hline & & Female & 3.03 & .724 & \\
\hline \multirow[t]{4}{*}{ Understand group membership } & \multirow[t]{2}{*}{ Education } & High school & 2.94 & .652 & \multirow{2}{*}{$.947(.344)$} \\
\hline & & College & 2.86 & .786 & \\
\hline & \multirow[t]{2}{*}{ Gender } & Male & 2.88 & .717 & \multirow{2}{*}{$-.085(.932)$} \\
\hline & & Female & 2.89 & .752 & \\
\hline \multirow[t]{4}{*}{ Pride in ethnic group } & \multirow[t]{2}{*}{ Education } & High school & 3.62 & .669 & \multirow{2}{*}{$2.962(.003 * *)$} \\
\hline & & College & 3.38 & .835 & \\
\hline & \multirow[t]{2}{*}{ Gender } & Male & 3.40 & .797 & \multirow{2}{*}{$-1.104(.270)$} \\
\hline & & Female & 3.49 & .784 & \\
\hline \multirow[t]{4}{*}{ Strong attachment to group } & \multirow[t]{2}{*}{ Education } & High school & 3.04 & .721 & \multirow{2}{*}{$-1.062(.289)$} \\
\hline & & College & 3.13 & .812 & \\
\hline & \multirow[t]{2}{*}{ Gender } & Male & 3.11 & .783 & \multirow{2}{*}{$.140(.889)$} \\
\hline & & Female & 3.09 & .781 & \\
\hline \multirow[t]{4}{*}{ Feel good about the culture } & \multirow[t]{2}{*}{ Education } & High school & 3.45 & .757 & $2468(014 *)$ \\
\hline & & College & 3.25 & .820 & $2.400(.014)$ \\
\hline & Gender & Male & 3.29 & .798 & $-476(635)$ \\
\hline & & Female & 3.33 & .806 & $-.4 / 0(.035)$ \\
\hline
\end{tabular}

Note. ${ }^{*} \mathrm{p}<.05 ; * * \mathrm{p}<.005 ; * * * \mathrm{p}=.001 ; * * * * \mathrm{p}<.001$.

There was no significant difference between male and female students in these two components, but significant difference was found in the ethnic identity search component for college and high school students $(t(341)=$ $-3.259, p=.001)$.

\subsection{Comparison of Ethnic Identity among Youth from Ethnic Majority and Minority Groups}

Bringing the Means of ethnic identity of youth from two ethnic groups: minority and majority into comparing, t-test confirmed no significant difference, but the item "Talked to others about the group" $(t(797)=-3.315, p$ $=.001$ ).

Table 5 presents the comparison of ethnic identity among youth from ethnic majority and minority groups. The means of two components of these two groups were high and rather equal $(M=3.02(S D=.403)$ for minority and $M=2.97(S D=.382)$ for the majority). When comparing ethnic identity of youth between ethnic minority and 
majority groups, there was only one significant difference found on the ethnic identity search component ( $t(797)$ $=-3.786, p<.001)$.

Table 5. Comparison of ethnic identity between ethnic majority and minority groups

\begin{tabular}{llrrr}
\hline Component & Ethnicity & $M$ & $S D$ & $t(p)$ \\
\hline Ethnic identity search & Major & 2.67 & .391 & $-3.786\left(.000^{* * * *}\right)$ \\
& Minor & 2.78 & .400 & \\
Affirmation, belonging, and commitment & Major & 3.18 & .482 & $-.251(.802)$ \\
\multirow{2}{*}{ Total } & Minor & 3.19 & .521 & \\
& Major & 2.97 & .382 & $-1.778(.076)$ \\
\hline
\end{tabular}

Note. $* \mathrm{p}<.05 ; * * \mathrm{p}<.005 ; * * * \mathrm{p}=.001 ; * * * \mathrm{p}<<.001$

\section{Discussion and Conclusion}

The findings revealed similar developmental trends of ethnic identity in youth from ethnic minority and majority groups in Dak Lak, Viet Nam with youth around the world. Phinney (1992) reported similar higher scores of ethnic identity components for high school students than for college students in the US. A research off French, Seidman, Allen, and Aber (2006) suggested that the development of ethnic identity was reported among early and middle adolescents in the US with similar scores. This trend could also be observed in Navajo adolescents (Jones \& Galliher, 2007).

There were similarities in the period of ethnic identity development of high school and college students with the stage of ethnic identity development of adolescents, college students and adults reported in French et al. (2006), Phinney (1992), Jones and Galliher (2007) and Yip et al. (2006). They reached stage 2 - "Foreclosed" - based on the stages of ethnic identity development that have been drawn and defined by Phinney (1989), which are: (1). Diffused: Diminutive or no consideration on racial without pure conceptualization of the issues; (2). Foreclosed: Slight or no investigation of ethnicity, but obvious clearness about one's own ethnicity. Senses about the ethnicity of each individual may be either positive or negative, based their socialization involvements; (3). Moratorium: Proof of investigation, together with some mix-up of the importance of one's own ethnicity; (4). Achieved: Confirmation of exploration, along with a clear, secure thoughtful and reception of one's own ethnicity. If one is in the foreclosed stage of ethnic development (being loyal to ethnic identity without taking discovered one's ethnic inheritance), it means is he or she might have a comparatively inexperienced view of the culture which he or she is committed to but lacking of the realitive recognition or appreciation about the convention and the motive behind that cultural practice or behavior. This could lead to the limitation in the experiences, change, or flexibility of one's view of their ethnic culture (Jones \& Galliher, 2007).

In Phinney's (1992) study, he found that Black partakers had meaningfully higher ethnic identity scores than did White and Hispanic counterparts. In this study, we found a higher ethnic identity score for the majority group than for minority groups, but the higher score had only significant difference in the component Ethnic identity search. Phinney $(1989,1992)$ proposed that White youth from European ethnic groups have not given much thought and also not very clear about ethnicity, so it would be hard to determine their ethnic identity stage. This brings us to the question: Do ethnic minority groups have a stronger ethnic identity than ethnic majority group because they often have to face racism in their daily life? Or the reason for this is that majority youth assume that the word "ethnic group" does not refer to themselves, but to others from minority groups (Andrews \& Lochner, 1989). Future research needs to examine ethnic identity in majority groups to answer this question.

In summary, this study was designed to explore ethnic identity of youth from ethnic majority and minority groups in Dak Lak, Viet Nam. Our findings highlight the "Foreclosed" status of ethnic identity of youth from both ethnic groups as well as both genders and both education levels. For the majority group, there were significant differences between genders for the affirmation, belonging, and commitment component and between high school and college students for the ethnic identity search component. For both components, females had significantly higher scores than males and college students had significantly higher scores than high school students. For ethnic minority groups, the score of the ethnic identity search component of college students was higher than that of high school students, but it was reversed for the affirmation, belonging, and commitment 
component. The scores of both components were higher for males than for females. There was no significant difference between genders in these two components, but a significant difference was found in the ethnic identity search component between education levels. Significant differences were only found in ethnic identity exploration between ethnic groups. Our findings were consistent with past research, which also showed the development of ethnic identity between ages (French et al., 2006; Jones \& Galliher, 2007; Phinney, 1992; Yip et al., 2006).

Because youth from ethnic majority group had a lower score on ethnic identity than ethnic minority groups, it is imperative that we continue to search for factors that influence the development of ethnic identity in majority groups. Beside of contributing to the very limited literatures in Viet Nam on ethnic identity, the present finding revealed the stronger ethnic identity of youth from ethnic minority groups than those from the ethnic majority group that raise the important issue for scientists as well as Vietnamese Government to work out finding the answers to the questions: What are the real reasons for that issue and is it a positive or negative issue? The reasons and the strategies that help youth from ethnic minority groups in Viet Nam can keep their strong ethnic identity in the modern complex social context is also a very interesting question needed to find out. Further studies should be conducted to understand more about the ethnic identity of ethnic groups in Viet Nam.

\section{References}

Andrews, M., \& Lochner, B. (1989). Ethnic identity issues in White tenth graders. Paper presented at the annual meeting of the Western Psychology Association, Reno, NV.

AJ, U.-T. (2004). Ethnic identity and self-esteem: Examining the role of social context. Journal of Adolescence, 27(2), 139-146. http://dx.doi.org/10.1016/j.adolescence.2003.11.006

Aradmin. (2012). Vietnamese ethnic groups. Retrieved from http://asiarecipe.com/vietnam/vn-information/ vietnamese-ethnic-groups.html

Baron, R. A., Byrne, D., \& Branscombe, N. R. (2006). Social psychology. USA: Pearson Education, Inc.

Daklak provincial people's committee portal. (2010). Retrieved from http://daklak.gov.vn/portal/page/portal/ daklak_en/daklak/tong-quan-kinhte-xahoi

Erikson, E. H. (1968). Identity: Youth and crisis. New York: Norton.

French, S. E., Seidman, E., Allen, L., \& Aber, J. L. (2006). The development of ethnic identity during adolescence. Developmental Psychology, 42(1), 1-10. http://dx.doi.org/10.1037/0012-1649.42.1.1

Jones, M. D., \& Galliher, R. V. (2007). Ethnic identity and psychosocial functioning in Navajo adolescents. Journal of Research on Adolescence, 17(4), 683-696. http://dx.doi.org/10.1111/j.1532-7795.2007.00541.x

Nguyen, T. T. T. (2008). The role of radio and TV in the life of ethnic minorities in Vietnam: Case study: the H'mong people in Lao Cai and Lai Chau province. Dissertation (MA), Indigenous Studies, University of Tromsø, Na Uy.

Phinney, J. S. (1989). Stages of ethnic identity development in minority group adolescents. Journal of Early Adolescence, 9, 34-49. http://dx.doi.org/10.1177/0272431689091004

Phinney, J. S. (1990). Ethnic identity in adolescents and adults: Review of research. Psychological Bulletin, 108(3), 499-514. http://dx.doi.org/10.1037/0033-2909.108.3.499

Phinney, J. S. (1992). The Multigroup Ethnic Identity Measure: A new scale for use with adolescents and young adults from diverse groups. Journal of Adolescent Research, 7(2), 156-176. http://dx.doi.org/10.1177/074355489272003

Phinney, J. S. (2000). Ethnic and racial identity: Ethnic identity. In A. E. Kazdin (Ed.), Encyclopedia of psychology (Vol. 3, pp. 254-259). New York: Oxford University Press.

Phinney, J. S. (2006). Ethnic identity exploration in emerging adulthood. In J. J. Arnett \& J. L. Tanner (Eds.), Emerging adulthood: Coming of age in the 21st century (pp. 117-134). Washington, DC: American Psychological Association.

Rayle, A. D., \& Myers, J. E. (2004). Counseling adolescents toward wellness: The roles of ethnic identity, acculturation, and mattering. Professional School Counseling, 8(1), 81-90.

Rotheram, M. J., \& Phinney, J. S. (1987). Introduction: Definitions and perspectives in the study of children's ethnic socialization. In M. J. Rotheram, \& J. S. Phinney (Eds.), Children's ethnic socialization (pp. 10-28). Newbury Park, CA: Sage. 
Smith, T. B., \& Silva, L. (2001). Ethnic identity and personal well-being of people of color: A meta-analysis. Journal of Counseling Psychology, 58, 42-60. http://dx.doi.org/10.1037/a0021528

Tajfel, H., \& Turner, J. (1986). The social identity theory of intergroup behavior. In S. Worchel, \& W. Austin (Eds.), Psychology of intergroup relations (pp. 7-24). Chicago, IL: Nelson-Hall.

Wikipedia. (2014). List of ethnic groups in Vietnam. Retrieved from http://en.wikipedia.org/wiki/List_of_ethnic groups_in_Vietnam

Yip, T., Seaton, E. K., \& Sellers, R. M. (2006). African American racial identity across the lifespan: Identity status, identity content, and depressive symptoms. Child Development, 77(5), 1504-1517. http://dx.doi.org/10.1111/j.1467-8624.2006.00950.x

\section{Copyrights}

Copyright for this article is retained by the author(s), with first publication rights granted to the journal.

This is an open-access article distributed under the terms and conditions of the Creative Commons Attribution license (http://creativecommons.org/licenses/by/3.0/). 